\title{
Effect of preemptive intravenous ketorolac and bupivacaine infiltration on post operative pethidine consumption - a comparative study
}

\author{
Jalal Uddin Ahmed', Md Shahidul Islam², Md Shafiqul Islam³, Mantosh Kumar Mandal ${ }^{4}$, \\ Mohammad Sirajul Islam ${ }^{5}$, Md. Shamsuzzoha ${ }^{6}$, Akhtaruzzaman AKM ${ }^{7}$
}

\begin{abstract}
${ }^{1}$ Associate Professor, Department of Anaesthesiology, Dhaka Dental College, ${ }^{2}$ Consultant, Department of Anaesthesiology, Dhaka Medical College \& Hospital, ${ }^{3}$ Assistant Professor, Shaheed Suhwardy Medical College \& Hospital, ${ }^{4}$ Assistant Professor, Department of Anaesthesiology, National Cancer Hospital and Research Institute, Mohakhali Dhaka, ${ }^{5}$ Consultant Anaesthesiologist, Sarail Up-Zilla Health Complex, B Baria, ${ }^{6}$ Assistant Professor, Dept. of Anaesthesia, Mansur Ali Medical College, Uttara, Dhaka, ${ }^{7}$ Professor of Neuroanaesthesia, Bangabandhu Sheikh Mujib Medical University, Shahbag, Dhaka-1000

Corresponding Author: Dr. Jalal Uddin Ahmed, Associate Professor, Department of Anaesthesiology, Dhaka Dental College, email: <jalal@gmail.com>
\end{abstract}

\begin{abstract}
Background: Preemptive analgesia significantly reduces postoperative analgesic requirement. Multi modal approach for preemption has greater range of benefit and its use in treating postoperative pain has gaining popularity.

Objectives: To observe the effect of preemptive bupivacaine infiltration and intravenous ketorolac on postoperative pethidine consumption in single and multiple preemptive techniques.

Methods: One hundred and twenty patients of ASA physical status I\&II requiring lower abdominal surgery under general anaesthesia were randomly allocated in four groups. Gr-A received bupivacaine infiltration and ketorolac injection, Gr-B received intravenous Ketorolac injection, Gr-C bupivacaine infiltration and $G r-D$ received nothing regarded as Control group. Data were analyzed by student's $t$ test, ANOVA and chi-square test as appropriate.
\end{abstract}

Results: Patients characteristics, duration of surgery, haemodynamic status were comparable in four groups. Pain intensity in VAS was significantly reduced in Gr-A $(p<0.00)$ than other three groups. Total pethidine consumption was also reduced significantly in Gr-A $(p<0.05)$.

Conclusion: Preemptive analgesics using in multiple modes gives better postoperative analgesia and patient comfort and less postoperative complications.

Key words- multimodal approach, postoperative pain, analgesia, ketorolac, infiltration, bupivacaine

(Journal of BSA, 2010; 23(1): 25-29)

\section{Introduction:}

Pain is an extra ordinary complex sensation which is difficult to define and equally difficult to measure in an accurate objective manner. The International Association for the Study of Pain (IASP) defines pain as an unpleasant sensory and emotional experience associated with actual or potential tissue damage or described in terms of such damage.

Peripheral tissue injury provokes modification in the responsiveness of the nervous system. Peripheral sensitization, a reduction in the threshold of nociceptive afferent peripheral terminal and central sensitization, an activity dependent increase in the excitability of spinal neurons; contributes together to post injury pain hypersensitivity state ${ }^{1}$. Damaged tissue produces two phases of sensory input. First they are associated directly with tissue damaging stimulus i.e. during surgery. Secondly results from inflammatory reaction to damaged tissue. These causes release of wide range of chemicals that activate chemo sensitive afferent directly, sensitizes high threshold nociceptors. The phase of sensory input occurs post operatively during period of wound healing. 
Post operative pain is a form of acute pain caused by noxious stimuli typically associated with neuroendocrine stress response that is proportional to pain intensity ${ }^{2}$. Moderate to severe acute pain regardless of site, affect nearly all organ function and may adversely influence postoperative pain management.

Postoperative pain can be reduced by pre-emptive analgesia. Pre-emptive analgesia implies analgesia directly as a result of reducing peripheral and or central sensitization. This type of management pharmacologically induces an effective analgesic state prior to surgical trauma by infiltration of the wound with local anaesthetics, central neural blockade or administration of opioids, NSAIDs or NMDA receptor agonist ketamine ${ }^{3}$.

Local anaesthetic act by binding to $\mathrm{Na}^{+}$channel, it slows the rate of depolarization, so don't alter resting membrane potential or threshold level and ketorolac act by inhibiting cyclooxygenase, enzyme responsible for biosynthesis of prostaglandin, prostacyclin and thromboxane ${ }^{4}$. NSAIDs also attenuate hyperalgesic state caused by sensitization of afferent nerve fibres by prostaglandin ${ }^{5}$.

\section{Materials and Methods:}

A total number of one hundred and twenty female patients requiring lower abdominal surgery were studied. The purpose of the study were clearly explained to each of the subject and recruited only after they had given their written consent. Selected patients were female, age ranging from 20 to 55 years, weight ranging from 30 to $80 \mathrm{kgs}$, ASA grade I \& II. Those who were with hypersensitivity to study drugs, peptic ulcer disease, gastritis, bleeding disorder, on anticoagulant therapy, respiratory, cardiac, hepatic, renal disease and patient not being motivated were excluded. They were divided into four groups, thirty in each group. Gr-A: bupivacaine infiltration and intravenous ketorolac after induction, Gr-B: intravenous ketorolac alone, Gr-C: bupivacaine infiltration after induction of anaesthesia and Gr- D: control group, no preemptive therapy.

All patients were examined pre-operatively and pre operative base line haemodynamic status was recorded. A $10 \mathrm{~cm}$ visual analogue scale (VAS) slide roller and verbal rating scale were used to assess level of postoperative pain. VAS and VRS scale was explained to the patient that one extreme of scale indicates no pain and the other is worst possible pain. PCA function was explained and pushing of PCA buttons practiced.

After pre-oxygenation for 3 minutes with $100 \%$ O2, general anaesthesia was induced with thiopental sodium $5 \mathrm{mg} / \mathrm{kg}$ intravenously and suxamethonium $2 \mathrm{mg} / \mathrm{kg}$ to aid tracheal intubation. Anaesthesia was maintained with $\mathrm{N} 2 \mathrm{O}(66 \%), \mathrm{O}_{2}(33 \%) \&$ Halothane (0.5\%). No opioid was used during the operation. Competitive muscle relaxant vecuronium $0.1 \mathrm{mg} /$ $\mathrm{kg}$ initially then $0.05 \mathrm{mg} / \mathrm{kg}$ incremental doses was used for skeletal muscle relaxation. Residual effect of competitive muscle relaxant was antagonized with neostigmine $40 \mu \mathrm{g} / \mathrm{kg}$ and atropine $20 \mu \mathrm{g} / \mathrm{kg}$ at the end of skin closer. In the postoperative period intravenous patient controlled analgesia (PCA) machine was attached with IV line by three way extension tube. A loading dose of pethidine $30 \mathrm{mg}$ given intravenously and PCA dose adjusted to 10 mg with lock out interval of 30 minutes. Patient was assessed at immediate post operative period, 4 hour afterward, 12 hour afterward and 24 hour after starting of operation (time of incision considered as zero hour).

Post operative complications e.g. nausea, vomiting, pruritus, allergic rash, hypotension, bronchospasm and respiratory depression etc was also studied among different groups. Patient satisfactions e.g. excellent, good, fair and poor among the groups and within the groups were also studied.

All results were expressed as mean $\pm \mathrm{SEM}$ or as percentage as applicable. Mean \pm SEM was calculated for each of the observation in 30 patients in each group. The data yielded from this study were compiled and analyzed with the help of students' t test, Chi-squire and ANOVA test as appropriate. A p value of $<0.05$ were considered as statistically significant.

\section{Results:}

One hundred and twenty female patients undergoing elective gynaecological surgery were included in this study. They were randomly allocated into four groups, 30 in each (Gr-A, Gr-B, Gr-C and Gr-D). They were matched for age ( $\mathrm{p}=$ $0.65)$, body weight $(\mathrm{p}=0.89)$ and ASA physical status $(\mathrm{p}=0.801)$. The mean age in Gr-A was $41.20 \pm 1.18$ yrs, in Gr-B was $39.87 \pm 1.48$, in Gr-C was $41.57 \pm$ 1.19 and in Gr-D $42.80 \pm 1.35$. Body weight of in Gr-A was 56.57 \pm 1.79 , in Gr-B 57.20 \pm 1.77 , in GrC 55.17 \pm 1.95 and in Gr-D 56.80 \pm 2.36 . 
Table-1

Characteristics of the study population

\begin{tabular}{lccc}
\hline $\begin{array}{l}\text { Groups / } \\
\text { variable }\end{array}$ & $\begin{array}{c}\text { Age } \\
\text { (years) }\end{array}$ & $\begin{array}{c}\text { Body weight } \\
(\mathrm{kg})\end{array}$ & $\begin{array}{c}\text { Duration of } \\
\text { Surgery } \\
\text { (minutes) }\end{array}$ \\
\hline Gr-A & $41.20 \pm 1.18$ & $57 \pm 1.79$ & $103.43 \pm 5.9$ \\
Gr-B & $39.87 \pm 1.48$ & $57.20 \pm 1.77$ & $101.33 \pm 5.5$ \\
Gr-C & $41.57 \pm 1.19$ & $55.17 \pm 1.95$ & $99.10 \pm 4.9$ \\
Gr-D & $42.80 \pm 1.35$ & $56.80 \pm 2.36$ & $99.33 \pm 4$. \\
\hline
\end{tabular}

Values are expressed as mean \pm SEM

Duration of surgery was recorded in minutes and it starts from skin incision to complete closure and strapping of the wound. In Gr-A total operation time was $103.43 \pm 5.9$, in Gr-B it was 101.33 \pm 5.5 , in Gr-C $99.10 \pm 4.9$ and in Gr-D 99.33 4.0 and no statistical significance difference were found $(p=0.44)$.

\section{Haemodynamic parameters}

Heart rate (HR), mean blood pressure and arterial oxygen saturation $\left(\mathrm{SpO}_{2}\right)$ were recorded from the immediate postoperative period (recorded as zero time) to the next twenty four hours in the postoperative ward.

\section{Heart rates:}

Changes in the heart rate in the immediate post operative period, 4 hours afterward, 12 hour after operation and 24 hour after operation in the next morning were recorded and it were highly significant $(\mathrm{P}<0.05)$ in $\mathrm{Gr}-\mathrm{A}$ than other three groups in all recoded period.

\section{Mean Blood Pressure}

Changes of mean blood pressure in all the four group scheduled intervals were not significant $(\mathrm{P}>0.05)$.

Arterial oxygen saturation was recorded also in same interval and there were no significant change in all four observation points $(\mathrm{P}>0.05)$.

\section{Measurement of pain intensity:}

Pain intensity was recorded by the help of a $10 \mathrm{~cm}$ long visual analogue scale (VAS) in the predetermined time period. VAS score showed significantly reduced in Gr-A at all observation period $(p<0.05)$ than other three groups.

\section{First analgesic demand:}

First analgesic demand was recorded after the operation in minutes. In Gr-A it was $407 \pm 9.5$, in Gr-B $147 \pm 6.2$, in Gr-C 298 \pm 7.7 and in Gr-D 106 \pm 8.4 minutes. It was highly significant in Gr-A than other three groups $(\mathrm{P}<0.00)$.

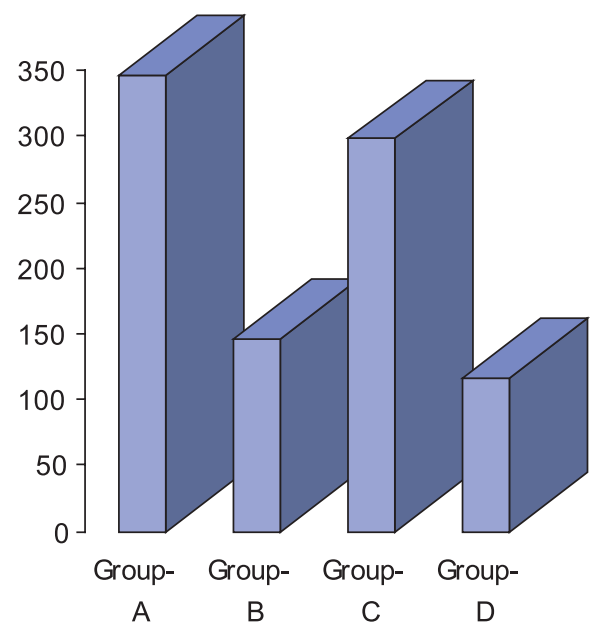

Fig.-1: Time of first demand of analgesics in minutes

In the post operative period in 24 hours of post operative ward the total amount of pethidine consumed in the different groups were shown Fig.2 . They were analyzed by ANOVA test and showed a significantly reduced amount of pethidine consumed $(p<0.05)$ in Gr-A than other three groups.

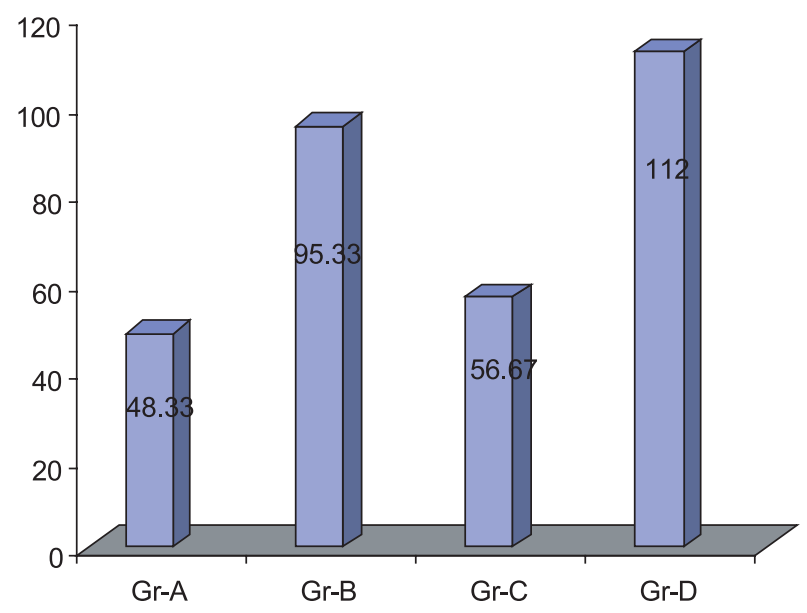

Fig.-2: Total pethidine consumption in twenty four hour

Patient satisfaction- Degree of patient satisfaction among the groups and within the groups was recorded by verbal rating scale (VRS) as- excellent, good, fair and poor. The results were found as in Gr- A: Excellent 40\%, Good 36.7\%, Fair $23.3 \%$, Poor-0\%. In Gr-B: no patient graded as excellent, good- $6.75 \%$, Fair- $36.7 \%$, Poor- $56.70 \%$. Gr. C- Exc. 6.7\%, Good-60\%, Fair- 30\%, Poor- 3.3\%. In Gr- D- Exc. 0\%, Good-6.7\%, Fair- 20\%, Poor$73.3 \%$. They were analysed by ANOVA and showed 
highly significant value $(\mathrm{p}<0.05)$ in Gr-A than other three groups.

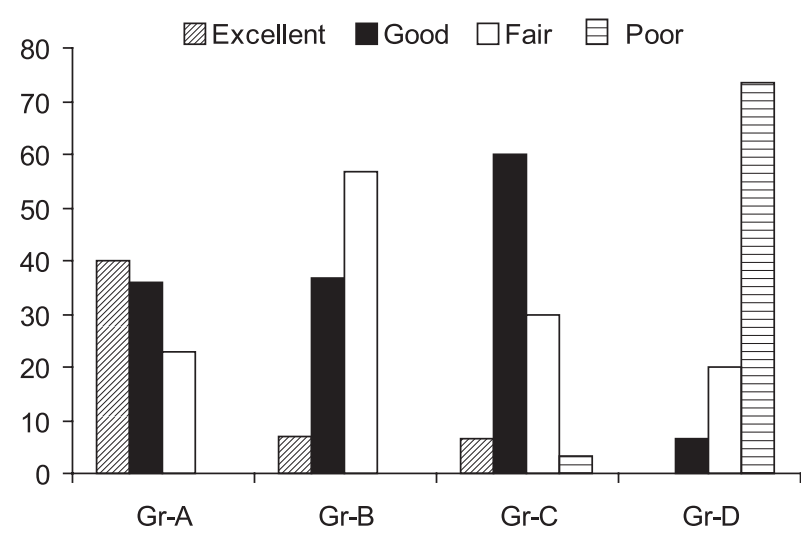

Fig.-3: Patients Satisfaction in four studied groups

\section{Postoperative complications:}

Postoperative complications like nausea, vomiting, pruritus, hypotension, bronchospasm and respiratory depression in four groups were recorded in predetermined time interval. The complications were less in Gr-A, than other three groups and it was highly significant $(p<0.05)$.

\section{Table-II}

Distribution of different types of complications in different time of four studied groups

\begin{tabular}{lcccc}
\hline $\begin{array}{l}\text { Groups } \\
\mathrm{n}=30\end{array}$ & $\begin{array}{c}\text { Gr-A } \\
\mathrm{n}=30\end{array}$ & $\begin{array}{c}\text { Gr-B } \\
\mathrm{n}=30\end{array}$ & $\begin{array}{c}\text { Gr-C } \\
\mathrm{n}=30\end{array}$ & $\begin{array}{c}\text { Gr-D } \\
\mathrm{n}=30\end{array}$ \\
\hline $\begin{array}{l}\text { Nausea and } \\
\text { / or vomiting }\end{array}$ & $10(33 \%)$ & $16(53 \%)$ & $14(46 \%)$ & $22(73 \%)$ \\
$\begin{array}{l}\text { Pruritus } \\
\text { Bronchospasm }\end{array}$ & - & $2(6 \%)$ & $3(10 \%)$ & $4(13 \%)$ \\
$\begin{array}{l}\text { Hypotension } \\
\begin{array}{l}\text { Respiratory } \\
\text { depression }\end{array}\end{array}$ & - & $1(3 \%)$ & $2(6 \%)$ & - \\
$\begin{array}{l}\text { No } \\
\text { complications }\end{array}$ & $20(67 \%)$ & $11(36 \%)$ & $11(36 \%)$ & $2(6 \%)$ \\
\hline
\end{tabular}

Data were expressed as number; within parenthesis are percentages over column total

\section{Discussion:}

Pre-emptive analgesia is an anti-nociceptive treatment that prevents establishment of altered processing of afferent input that amplifies pain. Concept of pre-emptive analgesia was formulated on basis of clinical observation ${ }^{6}$. Later on series of studies on animal has been performed ${ }^{7-10}$. Preemptive treatments are directed in the periphery at inputs along sensory axis and at central nervous system by using NSAIDs, local anaesthetics and opioids, either alone or in combination. With these underlying principles, therapeutic intervention is made $^{1}$.

Many studies that favour and promotes the idea of pre-emption and others against led us to review the use of pre-emptive drugs prior to similar type of major surgical procedures in near about identical types of patients and to see the difference between single and multiple pre-emptions. The postoperative response was reviewed by pain scoring, first urge for analgesic, total analgesic consumption and together with vital parameters like heart rate, blood pressure, respiratory rate and $\mathrm{SpO}_{2}$ up to the period of twenty four hours. We studied 120 patients randomly divided in 4 groups of 30 patients each. All cases performed lower abdominal surgery. Duration of operation was around 100 min. Four different groups received pre-emptive analgesic as per protocol. Time of first demand for analgesic was much later than other groups. Again total postoperative pethidine consumption was minimum in case of Gr- A in multiple pre-emptive groups than those receiving single pre-emptive. Those receiving no pre-emptive needed maximum postoperative opioids (Gr. D). Pethidine needed by bupivacaine only group (Gr. C) was also significantly less than group receiving ketorolac only (Gr. B). In our study, we have seen patients' maximum satisfaction with multiple pre-emptions than single pre-emption and pre-emption with bupivacaine infiltration gave better patient comfort than ketorolac pre-emption. Postoperative complication was seen more in patients receiving no pre-emption (Gr. D). Patients receiving pre-emption resulted in less postoperative pethidine consumption and less postoperative complication. Thus nausea, vomiting and respiratory depression were seen more in Gr. D.

\section{Conclusions:}

Under the condition of the present study, it can be concluded that pre-emptive application of analgesics using in multiple modes gives better post operative analgesia and patient comfort, less post operative complications than when used single analgesic technique. 


\section{References:}

1. Clifford J Woolf, Mun Seng Chong. Preemptive analgesia-treating post operative pain by preventing the establishment of central sensitization. Anaesth Analg1993; 77: 362-79.

2. Cousins MJ. Acute pain and the injury response; immediate and prolong effects. Regional Anaesthesia 1989; 14:162-178.

3. Morgan GE, Mikhail MS, Murray MJ. Pain management. Clinical Anaesthesiology. 3rd ed. New York, McGraw-Hill, 2002, 319.

4. Brooks PM, Day RO. Nonsteroidal antiinflammatory drugs- differences and similarities. N Engl J Med 1991; 13:324: 171625.

5. Vickers M D, Morgan M, Spencer P S J. Systemic Analgesics, Drugs in Anaesthetic and Intensive Care Practice, 8th ed., ButterworthHeinemann, 1999;
6. Crile GW. The kinetic theory of shock and its prevention through a nociception. Lancet 1913; 185: 7-16.

7. Woolf CJ, King AE. Physiology and morphology of multi-receptive neurons with $\mathrm{C}$-afferent fibre inputs in the deep dorsal horn of rat lumbar spinal cord. J Neurophysiol 1987; 58: 460-79.

8. Woolf CJ, Thompson SWN, The induction and maintenance of central sensitization is dependent on NMDA receptor activation: implications for the treatment of post injury pain hypersensitivity states. Anesthesiology 1991; 44:293-9.

9. Woolf CJ. Recent advances in the pathophysiology of acute pain. Br J Anaesth 1983; 63:139-46.

10. Woolf CJ. Evidence for a central component of post injury pain and hypersensitivity. The Lancet 1983; 308:686-8. 